\title{
Depression and Anxiety Disorders in a Sample of Saudi Persons with Brain Tumor
}

\author{
Abdulrahman Al-Anazi ${ }^{1}$, Maan A. Bari Saleh ${ }^{2}$, Abdel W. Awadalla ${ }^{2}$, Amen A. Bawazir ${ }^{3}$, Ahmed Ammar ${ }^{1}$, \\ Ibrahim Alluwimi ${ }^{1}$, Feras Alanazi ${ }^{1}$, Samar Barayan ${ }^{1} \&$ Abdelaziz M. Elfaki ${ }^{4}$ \\ ${ }^{1}$ Department of Neurosurgery, College of Medicine, Imam Abdulrahman Bin Faisal University, KSA \\ ${ }^{2}$ Department of Psychiatry, College of Medicine, Imam Abdulrahman Bin Faisal University, KSA \\ ${ }^{3}$ Department of Community and Environmental Health, College of Public Health and Health Informatics, King \\ Saud Bin Abdulaziz University for Health Sciences, KSA \\ ${ }^{4}$ Department of Psychiatry, King Fahad University Hospital, Khobar, KSA \\ Correspondence: Abdel W. Awadalla, Department of Psychiatry, College of Medicine, Imam Abdulrahman Bin \\ Faisal University, King Fahad University Hospital; Khobar, 31952, KSA.
}

Received: June 10, 2020 Accepted: July 22, 2020 Online Published: July 13, 2020

doi:10.5539/gjhs.v12n9p118 URL: https://doi.org/10.5539/gjhs.v12n9p118

\begin{abstract}
Background: Depression and anxiety (DA) are common in persons with brain tumor (PBT) and are associated with neurocognitive deficits. The terms DA and affective disorders are often used interchangeably in this study. Objective: This was a pilot study, conducted with the purpose of better assessing DA symptoms in association with socioeconomic and clinical characteristics in PBT.

Method: A cross-sectional study was conducted on a sample of PBT $(\mathrm{N}=102)$, recruited from a neurosurgical department. The tools employed were the Beck Depression Inventory-II (BDI-II) and the Hospital Anxiety and Depression Scale (HADS). The self-rating instruments proved feasible and reliable in screening for the severity of DA symptoms. The HADS is designed to measure the severity of anxiety and depressive symptoms in non-psychiatric hospital outpatients and does not assess the common somatic symptoms of these two disorders. The BDI-II evaluates the severity of depressive symptoms with items related to physical symptoms.
\end{abstract}

Results: Although our study did not, for the most part, yield results of statistical significance, it, however, demonstrated that anxiety and depressive disorders existed in PBT, showing a relatively higher rate in age groups 30-49 years.

Conclusion: It was unclear whether these symptoms were invalidated by response bias, participant's functional status, natural reaction to a fearing situation or just presentation of pseudodepression arose as a result of organic deficits. There is a need for further research to examine these factors.

Keywords: anxiety, affective disorder, brain tumor, depression, functional status, Saudi Arabia

\section{Introduction}

Brain tumors occur when abnormal cells form within the brain. Their cause is most often unknown. There are two types of brain tumor: malignant and benign brain tumors. Malignant tumors can be further divided into primary and secondary tumors. The former originates from the brain tissue and the latter (known as metastasis tumor) usually arises elsewhere in the body and immigrates to the brain. Secondary brain tumors are more common than primary, affecting nearly one in four patients with cancer (World Health Organization [WHO], 2014; National Cancer Institute, 2014). In adults, the most common types of cancers are astrocytomas, meningiomas and oligodendrogliomas, and in children, the most common types are medulloblastomas and gliomas (National Cancer Institute, 2014; WHO, 2012). On the other hand, benign brain tumors are the most prevalent, slow-growing and are located at the base of the skull or lower portion of the spine. It is found in people aged 50 years or greater. The common types include adenomas, lipomas and myomas, among others (Wilson, Waugh, Chambers, Grant, \& Ross; 2006). Symptoms of brain tumors vary depending on the part of the brain involved and may include headaches, seizures, problems with vision, vomiting and mental changes (National Cancer Institute, 2014a, 2014b; WHO, 2014). Most common psychiatric symptoms reported by persons with brain tumor (PBT) are associated with 
affective changes (e.g. depression, mania, anxiety), psychotic symptoms, panic attacks, anorexia, changes in personality and memory difficulties (Moise \& Madhusoodanan, 2006).

\subsection{Brain Tumor in Saudi Arabia.}

In the early 1980s, the first study on PBT was conducted by a group of local researchers (Chowdhary, Ibrahim, Sohaibani, \& Boehme, 1987) to establish a baseline for the incidence of brain tumor among a relatively homogenous Saudi population of a small proportion of immigrant workers. The data was collected at King Fahad University Hospital (KFUH) in Khobar, involving participants who received pre-and post-surgical treatment. The study findings were compared with similar previous findings, resulting in two points of interests: First, the incidence of meningioma among Saudi participants was found to be significantly higher at $26 \%$, compared to 12-16\% reported by similar studies (Russel \& Rubinstein, 1971; Zulch \& Wechsler, 1968; Zulch, 1956); second, the incidence of medulloblastoma was also higher at $11 \%$ among Saudis, compared to $7-8 \%$ reported by two earlier studies from Western countries (Russel \& Rubinstein, 1971; Zulch, 1956).

Several studies suggest a link between brain tumor and affective disorders. For instance, a study aimed to explore the impact of supratentorial brain tumor on affective symptoms of adult patients (Richter, Jenewein, Krayenbu, Woernle, \& Bellut, 2016). The authors employed screening and functional status instruments (i.e. BDI-II, HADS, Karnofsky Performance Status [KPS]) to study the impact of a supratentorial primary brain tumor on affective symptoms of adult patients preoperatively. The results showed significantly higher scores in female patients with lower functional status. Higher scores were also found in male patients with a WHO grade-4 tumor stage, compared to female patients. It is argued that functional status could be the cause of reflecting affective symptoms in PBT (Hill et al., 2016). This was supported by Overcash's (2015) study, which found that cancer patients diagnosed with depression were more likely to report problems with cognitive deficits and activities of daily living (ADL). In a similar vein, Huang et al. (2017) conducted a meta-analysis study to investigate the association between affective symptoms and brain tumor using a screening test battery, including BDI-II and HADS. The types of tumors investigated included glioma, meningioma and pituitary adenoma. The authors estimated the prevalence of depression to be $21.7 \%$. Other studies found DA in PBT to be common in both preoperative and postoperative periods (Litofsky et al., 2004; Pringle, Taylor, \& Whittle, 1999).

Depression and anxiety (DA) represent one of the major groups of disorders seen in PBT, showing high prevalence rates ranging from $10 \%$ to $40 \%$ and even nearly $90 \%$ in some reports (Charkavluik, Steiblience, Tamasauskas, Deltuva, \& Bunevicius, 2014; Litofsky et al., 2004). As defined by DSM-5 (American Psychiatric Association [APA], 2013), anxiety disorders include disorders that share features of excessive anxiety and fear and related behavioral disturbances. The emotional states of anxiety and fear are closely related to primitive emotions that function to preserve life either by surges of autonomic arousal or uncomfortable somatic reactions (APA, 2013; Lang, Davis, \& Ohman, 2000; Barlow, 2002). On the other hand, depression is viewed as the most common mental health disorder and a significant contributor to the global burden of disease worldwide (WHO, 2014; 2012). It is represented in the presence of various symptoms of sadness, loss of interest, lack of energy, thoughts of self-harm or suicide and feeling of guilt and worthlessness (APA, 2013). DA symptoms can provide insight into where the tumor might be located within the brain. Some studies have concluded that primary brain tumor in the right hemisphere was significantly associated with anxiety disorder, whereas the left hemisphere tumor was associated with a depression-like syndromes (Oliveira-Maia, Ruivo, \& Barahona-Corrêa, 2014; Mainio et al., 2003; Allen, 2002). Allen (2002) suggested another interpretation that depression in persons with brain insult may convey a healthy sign of awareness about deficits. Other studies concluded that a combination of both disorders could be indicative of left cortical lesions (Castillo, Starkstein, Fedoroff, Price, \& Robinson, 1993).

To date, there has been no study investigating mental changes in PBT in Saudi Arabia. Our literature search yielded only a single published study investigating psychological status among Saudi cancer patients (Ahmed et al., 2018). Therefore, the purpose of the present study was to assess the levels of DA in PBT and to analyze the effect of mood changes in participants' sociodemographic and clinical characteristics. Based on the literature on this topic worldwide (Richter et al., 2016; Pringle, Taylor, \& Whittle, 1999; Mainio et al., 2003), we hypothesized the following: first, there would be a significant association between brain tumor and DA disorders; second, younger participants would more likely exhibit DA than older ones; third, severity of depression would be discrepant among various age groups and genders; fourth, there would be an association between sociodemographic status, clinical characteristics and affective changes in participants with brain tumor. 


\section{Methods}

\subsection{Participants and Setting}

The participants in this study were 102 Saudi nationals with brain tumors, recruited from the Inpatient Department of Neurosurgery at King Fahad University Hospital (KFUH) in Khobar - one of the largest teaching hospitals in the Eastern Province (EP). The participants met the eligibility criteria related to sociodemographic (age $\geq 18$ years of age and both genders) and clinical (stable disease, distinct diagnosis of brain tumor type) characteristics and of speaking and reading Arabic. Patients with a history of aphasia, cognitive deficits, comorbidity and current use of psychotropic medication were excluded from the study.

\subsection{Procedure}

This was a pilot study, aimed at assessing DA symptoms in association with socioeconomic and clinical characteristics in PBT. Consent procedures were approved by the IRB Committee at KFUH. Informed consent was obtained from each participant before the study. All the interested participants were approached by the researchers and were requested to provide information on their level of education, occupation, socioeconomic and marital status, and then to fill out two questionnaires of BDI-II and HADS, evaluating the severity of DA symptoms. The objectives of the study and protected confidentiality were explained, and the participants were informed that their participation was voluntary and that they may withdraw from the research for any reason without penalty. They were requested to begin with filling out the sociodemographic clinical variables and then proceed to the screening instruments. The researchers were available to respond to participant inquiries, and, finally, the completed questionnaires were collected.

\subsection{Measures}

The present study used a cross-sectional design and employed brief yet sensitive and specific assessment instruments, namely Beck Depression Inventory-II (BDI-II) (Al-Turkait \& Ohaeri, 2010) and Hospital Anxiety and Depression Scale (HADS) (Bjelland, Dahl, Haug, \& Neckelmann, 2002).

\subsubsection{Beck Depression Inventory-II (BDI-II)}

The recent Arabic version of BDI-II was validated by Al-Turkait and Ohaeri (2010) to assess the level of depression severity in a normative sample of the Kuwaiti population. Similar to the original BDI-II (Beck, Steer, \& Brown, 1996; Beck \& Steer, 1993), the Arabic BDI-II is a multiple-choice self-rated scale, composed of 21 items that evaluate key symptoms of depression with individual items scored 0 to 3 points for a total score range of 0 to 63. The cut-off scores are classified as minimal (0-13), mild (14-19), moderate (20-28) and severe (29-63). The prevalence of depression identified using BDI-II after neurosurgery for brain tumor was 35\% (Mainio et al., 2006). The internal consistency (Cronbach's alpha) for all 21 items, using the responses of all participants, was 0.83 (Al-Turkait \& Ohaeri, 2010).

\subsubsection{Hospital Anxiety and Depression Scale (HADS)}

The Arabic version of HADS was validated recently by Terkawi et al. (2017), in a sample of participants admitted for surgical procedure to two tertiary care centres in the capital city Riyadh. The HADS produces two scales, one for anxiety (HADS-A; 7 items) and one for depression (HADS-D; 7 items). It is a 14-item measure with a 4-point severity scale (from 0 to 3 ), designed to assess DA symptoms in medical patients, with an emphasis on reducing the impact of physical illness on the total score. A score greater than or equal to 11 on either scale indicates a definitive case. A score of $0-7$ is considered normal, 8-10 as a borderline case and 11-21 as a definite case of anxiety and/or depression (Terkawi et al., 2017; Zigmond \& Snaith, 1983). Studies show that symptoms of DA in PBT measured by HADS is common practice with preoperative depressive symptoms as they are more likely to be associated with shorter survival time in certain types of tumors (Bunevicius, Tamasuskas, Deltuva, Tamasuskas, \& Bunevicius, 2017; Huang et al., 2017). Cronbach's alpha for the HADS anxiety subscale was 0.83 ( $95 \%$ confidence interval: $0.79-0.88)$ and for the HADS depression, the subscale was $0.77(0.7-0.83)$.

\subsection{Data Analysis}

All analyses were performed using the Statistical Package of Social Sciences (SPSS) version 20.0. The relationships between various sociodemographic and clinical factors (i.e. gender, age groups, education, marital status, tumor location, visitation, diseases, etc.) were analyzed using descriptive and inferential methods (frequencies, percentages, Student's t-test, Chi-square and coefficient correlation). The Severity levels of DA in PBT were analyzed using two screening instruments. A probability value of $<0.05$ was considered significant. 


\section{Results}

\subsection{Reliability}

In this study, reliability estimates for both BDI-II and HADS were tested as follows: BDI-II Cronbach's alpha obtained was 0.89 (21 items) and HADS ranged from 0.82 (hospital anxiety; HADS-A; 7 items) to 0.84 (hospital depression; HADS-D; 7 items). The obtained reliabilities were almost comparable to Cronbach's alpha of the original version and other existing Arabic versions (Terkawi et al., 2017; Zigmond \& Snaith, 1983).

Table 1. Socioeconomic characteristics of participants with brain tumour $(\mathrm{N}=102)$

\begin{tabular}{llc}
\hline Characteristics & Categories & No (\%) \\
\hline \multirow{2}{*}{ Gender } & Male/ & $40(39.2)$ \\
& Female & $62(60.8)$ \\
\hline \multirow{2}{*}{ Age group } & $<30$ yrs & $22(21.6)$ \\
& $30-49$ yrs & $49(48.0)$ \\
\hline \multirow{2}{*}{ Education } & $\geq 50$ yrs & $31(30.4)$ \\
\hline \multirow{2}{*}{ Occupation } & Non-univ & $62(60.8)$ \\
& University & $40(39.2)$ \\
\hline \multirow{2}{*}{ Marital status } & Employed & $34(35.8)$ \\
\hline \multirow{2}{*}{ Socioeconomic Status (SES) } & Unemployed & $61(64.2)$ \\
\hline \multirow{2}{*}{ Previous visits } & Married & $72(70.6)$ \\
& Unmarried & $30(29.4)$ \\
\hline
\end{tabular}

Table 1 shows the sociodemographic characteristics of the participants. The mean age of the all participants was 41.4 years $(\mathrm{SD}=14.3$ years) and ranged from 18 to 73 years, with higher percentage shown by the female gender (60\%), age group of 30-49 years (48.0\%), non-university graduates $(60.8 \%)$, non-employed $(64.2 \%)$ and married (70.6\%) participants. Except for one participant who was received by the Outpatient Department (OPD) or as an emergency case, all the others reported no previous visits to the tertiary care hospital. The results showed that a little more than a quarter $(28.7 \%)$ of participants reported on their SES.

Table 2. Clinical characteristics of participants with DA disorders

\begin{tabular}{llc}
\hline Characteristics & Categories & No (\%) \\
\hline \multirow{3}{*}{ BDI-II } & None & $49(48.0)$ \\
& Mild & $27(26.5)$ \\
& Moderate & $17(16.7)$ \\
& Severe & $9(8.8)$ \\
\hline \multirow{2}{*}{ HADS-D } & None & $80(81.6)$ \\
& Mild & $16(16.3)$ \\
& Moderate & $2(2.0)$ \\
\hline
\end{tabular}




\begin{tabular}{llc}
\hline & None & $79(80.6)$ \\
HADS-A & Mild & $15(15.3)$ \\
& Moderate & $4(4.1)$ \\
\hline \multirow{2}{*}{ Diagnosis } & Malignant & $20(24.1)$ \\
& Benign & $63(75.9)$ \\
\hline \multirow{2}{*}{ Location } & Cortical & $25(33.8)$ \\
& Ventric \& paraventr & $22(29.7)$ \\
& Posterior fossa & $21(28.4)$ \\
\hline
\end{tabular}

Table 2 shows the levels of DA among the participants. On BDI-II, nearly half of the participants ( $\mathrm{n}=49 ; 48 \%)$ reported no signs of depressive symptoms, while the rest were found to exhibit mild (26.5\%), moderate (16.7\%) and severe $(8.8 \%)$ depression. On the other hand, on HADS-D, a higher percentage of participants $(81.6 \%)$ reported no symptoms of depression and the findings were nearly identical to those from HADS-A (80.6\%) symptoms. The majority of participants were diagnosed with benign tumors $(75.9 \%)$, whereas nearly one-quarter $(\mathrm{n}=20 ; 24.1 \%)$ were diagnosed with a malignant brain tumor. The tumor location was distributed in percentage as follows: cortex $(33.8 \%)$, ventricular and paraventricular $(29.7 \%)$, posterior fossa $(28.4 \%)$ and sellar and suprasellar area $(8.1 \%)$.

Table 3. Association between DA and sociodemographic characteristics

\begin{tabular}{|c|c|c|c|c|c|c|c|}
\hline \multirow{2}{*}{ Characteristics } & & \multicolumn{2}{|c|}{ Depression } & \multicolumn{2}{|c|}{ Depression (HADS-D) } & \multicolumn{2}{|c|}{ Anxiety (HADS-A) } \\
\hline & & N (\%) & p-value & No $(\%)$ & p-value & No $(\%)$ & p-value \\
\hline \multirow{2}{*}{ Gender } & Male & $17(32.1)$ & \multirow{2}{*}{0.125} & $7(38.9)$ & \multirow{2}{*}{0.991} & $4(21.1)$ & \multirow{2}{*}{0.077} \\
\hline & Female & $36(67.9)$ & & $11(61.1)$ & & $14(78.9)$ & \\
\hline \multirow{3}{*}{ Age group } & $<30$ yrs & $11(20.8)$ & \multirow{3}{*}{0.567} & $4(22.2)$ & \multirow{3}{*}{0.959} & $4(21.1)$ & \multirow{3}{*}{0.804} \\
\hline & $30-49$ yrs & $28(52.8)$ & & $8(44.4)$ & & $8(42.1)$ & \\
\hline & $\geq 50 \mathrm{yrs}$ & $14(26.4)$ & & $6(33.3)$ & & $7(36.8)$ & \\
\hline \multirow{2}{*}{ Education } & non-univ & $33(62.3)$ & \multirow{2}{*}{0.750} & $14(77.8)$ & \multirow{2}{*}{0.111} & $4(73.7)$ & \multirow{2}{*}{0.214} \\
\hline & university & $20(37.7)$ & & $4(22.2)$ & & $5(26.3)$ & \\
\hline \multirow{2}{*}{ Marital Status } & unmarried & $19(35.8)$ & \multirow{2}{*}{0.138} & $4(22.2)$ & \multirow{2}{*}{0.393} & $4(21.1)$ & \multirow{2}{*}{0.314} \\
\hline & married & $34(64.2)$ & & $4(77.8)$ & & $15(78.9)$ & \\
\hline
\end{tabular}

Table 3 shows no significant association between DA and sociodemographic characteristics (i.e. gender, education, age groups and marital status). However, female gender, those in the age group of 30-49 years, non-university graduates and married participants scored higher on DA scales. 
Table 4. Association between DA and clinical characteristics

\begin{tabular}{|c|c|c|c|c|c|c|c|}
\hline \multirow{2}{*}{ Characteristics } & & \multicolumn{2}{|l|}{ BDI-II } & \multicolumn{2}{|c|}{ Depression (HADS-D) } & \multicolumn{2}{|c|}{ Anxiety (HADA) } \\
\hline & & No (\%) & p-value & No (\%) & p-value & No $(\%)$ & p-value \\
\hline \multirow{2}{*}{ Diagnosis } & Malignant tmr & $10(23.8)$ & \multirow{2}{*}{0.91} & $3(20.0)$ & \multirow{2}{*}{0.661} & $2(14.3)$ & \multirow{2}{*}{0.334} \\
\hline & Benign tmr & $32(76.2)$ & & $12(80.0)$ & & $12(85.7)$ & \\
\hline \multirow{2}{*}{ Neuro-deficit } & Yes & $24(53.3)$ & \multirow{2}{*}{0.049} & $9(60.0)$ & \multirow{2}{*}{0.132} & $7(46.7)$ & \multirow{2}{*}{0.722} \\
\hline & No & $21(46.7)$ & & $6(40.0)$ & & $8(53.3)$ & \\
\hline \multirow{2}{*}{ Complication } & Yes & $7(6.3)$ & \multirow{2}{*}{0.289} & $5(33.3)$ & \multirow{2}{*}{0.204} & $4(26.7)$ & \multirow{2}{*}{0.566} \\
\hline & No & $36(3.7)$ & & $10(66.7)$ & & $11(73.3)$ & \\
\hline \multirow{2}{*}{ Seizure } & Yes & $5(11.4)$ & \multirow{2}{*}{0.087} & $3(20.0)$ & \multirow{2}{*}{0.879} & $3(20.0)$ & \multirow{2}{*}{0.879} \\
\hline & No & $39(88.6)$ & & $12(80.0)$ & & $12(80.0)$ & \\
\hline \multirow{2}{*}{$\begin{array}{l}\text { Surgical } \\
\text { treatment }\end{array}$} & Yes & $38(86.4)$ & \multirow{2}{*}{0.58} & $15(100.0)$ & \multirow{2}{*}{0.060} & $15(100.0)$ & \multirow{2}{*}{0.060} \\
\hline & No & $6(13.6)$ & & $0(0.0)$ & & $0(0.0)$ & \\
\hline \multirow{2}{*}{$\begin{array}{l}\text { Adjuvant } \\
\text { therapy }\end{array}$} & Yes & $7(17.1)$ & \multirow{2}{*}{0.63} & $1(8.3)$ & \multirow{2}{*}{0.450} & $2(15.4)$ & \multirow{2}{*}{0.976} \\
\hline & No & $34(2.9)$ & & 11(91.7) & & $11(84.6)$ & \\
\hline \multirow{4}{*}{ Location } & Cortical & $13(4.2)$ & \multirow{4}{*}{0.09} & $5(47.0)$ & \multirow{4}{*}{0.663} & $4(33.3)$ & \multirow{4}{*}{0.555} \\
\hline & Posterior fossa & $8(21.1)$ & & $4(33.3)$ & & $5(41.7)$ & \\
\hline & Vent \& paravent & $16(42.1)$ & & $3(25.0)$ & & $3(25.0)$ & \\
\hline & Sellar \& supraslr & $1(2.6)$ & & $0(0.0)$ & & $0(0.0)$ & \\
\hline
\end{tabular}

Table 4 shows a significant association between neurological deficit and location of brain tumor with the level of depression $(p=0.049)$ but not with anxiety $(p=0.72)$. All other clinical variables (i.e. diagnosis, complication, seizure, surgical treatment and adjuvant therapy) did not yield a significant result $(\mathrm{p}>0.05)$. However, the association between DA and surgical treatment was barely below the level of significance $(\mathrm{p}=.06)$, indicating a possible assumption that a similar study with a larger sample size might yield a statistically significant result for the same association.

\section{Discussion}

The results showed that DA were a common in PBT, although no significant association was found between DA and sociodemographic and clinical characteristics (except for neurological deficit for depression). More than half (52\%) of the participants on BDI-II endorsed having depression, compared to nearly one-fifth, who endorsed having anxiety (19.4\%) and depression (18.3\%) on HADS. A compatible result was also found on HADS between participants who did not endorse symptoms of anxiety $(80.6 \%)$ and depression $(81.6 \%)$. This indicates sufficient evidence of reliability and consistency of the screening instruments in identifying affective changes in the participants. Similar findings on HADS were reported by Prindle et al. (1999), who found that $30 \%$ of their participants with intracranial tumors suffered from anxiety and $16 \%$ from depression. However, contradictory findings support the argument that the symptoms may not be related to brain tumor and may be reactions to situational fear, awareness signalling organic deficits (Allen, 2002), pseudodepression with negative symptoms of apathy or lack of concern and tendency to isolate (Chirchiglia, 2018; Huang et al., 2017). Hence, there is a need for thorough cognitive assessment to determine the PBT functional levels in various cognitive domains.

\subsection{Diagnosis and Location}

The main type of brain tumor diagnosed was benign (75.9\%), as more than one-third (33.8\%) of the cases were that of cortical areas. The literature is replete with reports describing disturbance in the functioning of cortical areas which might lead to affective disorders (Chirchiglia, 2018; Bunevicius et al., 2017; Wiedemann, et al., 1999). Wellish, Kaleita, Freeman, Cloughesy, and Goldman (2002) found tumor location in the frontal region to be the key predictor of major depressive disorder. Hence, in our study, this could partly be explained by the positive link between clinical neurological deficit and depression $(\mathrm{p}<0.5)$. Generally, participants who were female, non-university graduates, married and in the age group 30-49 years tended to show a considerable rate of DA 
symptoms (see Table 3). Our findings related to the presence of affective changes were consistent with the findings noted in Richter et al.'s (2016) study that used similar self-ratings, except for Hamilton Depression Rating Scale (HDRS).

\subsection{Age Group and Severity Level}

The affective changes were somewhat discrepant across the ages with depression (52\%) more than anxiety (19.4\%) reported to be more common in the age group 30-49 years. The reverse was true for Arnold et al.'s (2008) study reporting higher rates of anxiety (48\%) than depression $(41 \%)$ in their patients with primary brain tumors. However, our hypothesis about younger participants exhibiting more affective symptoms than older ones was not upheld.

The three items of BDI-II associated with "guilt feelings, "inability to work" and "somatic symptoms" were severely endorsed by at least half of the participants. Although religious beliefs and practices in Saudi society are vital for coping better with physical pain and illnesses, they may, however, increase participants' sense of guilt and failure of being unable to live up to their high religious standards (Bonelli, Dew, Koenig, Rosmarin, \& Vasegh, 2012). Another possible explanation might be related to the participants' perception of their physical pain and illness as the wrath or punishment from God due to personal sin or rebellion. In their study of the belief system among 110 Saudi persons with epilepsy, Alkhamees, Selai, and Shorvon (2015) found that $83 \%$ of participants attributed the cause of their illness to the will of God, whereas $40 \%$ believed it was a source of punishment from God. However, Allen's (2002) study revealed a different view that the highly endorsed somatic symptoms in persons with neurological insult could indicate a perceptual amplification of bodily sensation and symptoms and a means for interpersonal secondary gains.

Our study also showed that $75 \%$ of participants aged $27-55$ years (mean 41.4; $\mathrm{SD} \pm 14.3$ ) had high school or college education and more than one-third (35.8\%) were able to work. A low level of participants' work productivity severely endorsed in "inability to work" item suggested a high level of depressive symptoms or a broader array of neuropsychological deficits associated with difficulty processing effortful tasks such as visuospatial ability, psychomotor speed and time management (Nugent et al., 2014; Allen, 2002). Hence, further research is warranted to elucidate the impact of affective changes on PBT cognitive functions in the workplace.

\subsection{Gender}

Our study indicated a high percentage of DA among women than among men. Various explanations for this phenomenon have been proposed. One physiological factor behind more women developing depression and benign brain tumors than men is that the former have higher levels of estrogen, which tends to be more prone to mood disorders and is linked to women's emotional wellbeing (Arnold et al., 2008). D'Angelo et al. (2008) found postoperative depression to be directly correlated to the female gender. Other key factors related to lifestyle, the environment and socio-culture could contribute to the gender differences with more Saudi women than men exhibiting affective reactions to stressful situations (Shors \& Leuner, 2003).

\subsection{Marital Status}

Although it was not statistically significant, married participants endorsed more symptoms of DA than unmarried participants. Inconsistent findings reported by other studies indicated more depression among unmarried participants than married ones and that marriage or caregiving had a significant impact on prognosis and treatment of brain tumors and other mental disorders (Arnold et al., 2008; Hussain, Lenner, Sundquist, \& Hemminki, 2008; Schubart, Kinzie, \& Farace, 2008).

\subsection{Level of Education}

Participants with non-university education showed a greater tendency toward DA than participants with university education. These results parallel the findings of Arnold et al. (2008), who found individuals with college-level education to be much less likely than those with no college education to have anxiety, depression or both. A possible explanation could be that the PBT with higher education levels are more aware of their psychological and physical needs and are therefore able to care more for their health and willing to receive more effective interventions early on (Xie, Yang, Liu, \& Zhao, 2018; Hussain et al., 2008). However, the education level may influence affective disorders through income. For instance, Ahmed et al.'s (2018) study found that a college degree with low earnings (less than SR 5,000 $\approx \$ 1,333$ ) could play a role in the presence of affective disorders among Saudi cancer patients. In other words, individual income could adversely affect overall general health and psychological wellbeing in PBT. 


\subsection{Strengths and Limitations}

One of the strengths of this study was that our findings were in agreement with other previous studies (Bunevicius, Tamasauskas, Deltuva, Tamasauskas, \& Bunevicius, 2013; Ahmed et al., 2018; Huang et al., 2017; Mainio et al., 2003), indicating higher incidence rates of affective disorders among PBT. Also, we used validated Arabic instruments with high-reliability standards to better assess our participants. However, the present study has several limitations. First, the participants were all PBT from a single university hospital (KFUH). Thus, the affective changes they described may not be generalizable to other health settings throughout the Kingdom. Second, the sample size was small and it could be the reason that most clinical variables did not yield statistically significant results or just showed a certain trend toward marginal significance such as seizure $(\mathrm{p}=0.087)$ and location $(\mathrm{p}=$ 0.09 ) variables in relation to affective disorders. We hope that future research will involve a larger sample size with a control group to supplement the findings of the present study. Third, the diagnosis of affective symptoms was based entirely on screening instruments rather than on more clinically valid diagnostic methods (APA, 2013) and the literature demonstrated that response bias (e.g. social desirability bias) of self-ratings may have affected the resulting outcome (Krumpal, 2013). Fourth, the study was also limited by the exceptionally high non-response rates among persons with low socioeconomic positions as only $3(2.9 \%)$ participants were willing to report on their income, which could affect the accuracy of the analysis and interpretation of the results. In our experience, we found refusal to be the most common reason for non-response and it might be viewed socio-culturally as too sensitive for participants to report their income in an affluent conservative society. A non-response rate due to refusal in lower socioeconomic persons was also reported by other researchers (Ekholm, Gundgaaard, Rasmussen, \& Hansen, 2010).

\section{Conclusion}

We conclude that brain tumor can be associated with a variety of affective disorders such as depression and anxiety. Although our study did not, for the most part, yield statistically significant results, it did demonstrate a considerable rate of DA in the participants. It was unclear whether the affective disorders were of a functional origin or occurred as a reaction to the brain tumor. Some studies suggested that an unexplained treatment-resistant depression could be a sign of brain tumor with deleterious effects on cognitive functioning (Allen, 2002, Arnold et al., 2008; Huang et al., 2017). Therefore, a detailed history of mental states and reliable screening instruments for DA in a routine neuro-oncology setting could potentially improve recognition of affective changes in PBT (Pranckeviciene \& Bunevicius, 2015). This further suggests the need for increased attention to PBT who are screened positive for affective disorders to be referred to a mental health provider for further evaluation before initiating adjuvant therapies or surgical resection.

\section{Acknowledgements}

We are grateful to the authorities of King Fahad University Hospital for their valuable assistance in consenting to and facilitating data collection for the study. We also wish to thank the participants and their families for their valuable cooperation and contributions.

\section{Declaration of Authorship}

The first and second authors (AA\& MABS) designed and directed the study. AWA contributed to the interpretation of the results and $\mathrm{AAB}$ analyzed the data. The remaining co-authors participated in data collection. All authors contributed to write-up and revision of the manuscript.

\section{Competing Interests Statement}

The authors declare that they have no competing interests.

\section{References}

Ahmed, A. E., Albalawi, A. N., Qureshey, E. T., Qureshey, A. T., Yenugadhati, N., AL-Jahdali, H., \& Jazieh, A. (2018). Psychological symptoms in adult Saudi Arabian cancer patients. Breast Cancer - Targets and Therapy, 10, 153-159. https://doi.org/10.2147/BCTT.S168139

Alkhamees, H. A., Selai, C. E., \& Shorvon, S. D. (2015). The beliefs among patients with epilepsy in Saudi Arabia about the causes and treatment of epilepsy and other aspects. Epilepsy and Behavior, 53, 135-139. https://doi.org/10.1016/j.yebeh.2015.10.008

Allen, J. B. (2002). Treating patients with neuropsychological disorders: A clinician's guide to assessment and referral. American Psychological Association: Washington, DC. https://doi.org/10.1037/10440-000

Al-Turkait, F. A., \& Ohaeri, J. U. (2010). Dimensional and hierarchical models of depression using the Beck 
Depression Inventory-II in an Arab college student sample. BMC Psychiatry, $10,60$. https://doi.org/10.1186/1471-244X-10-60

American Psychiatric Association. (2013). Diagnostic and Statistical Manual of Mental Disorders (5th ed.). Arlington, VA: Author. https://doi.org/10.1176/appi.books.9780890425596

Arnold, S. D., Forman, L. M., Brigidi, B. D., Carter, K. E., Schweitzer, H. A., Quinn, H. E., ... Raynor, R. H. (2008). Evaluation and characterization of generalized anxiety and depression in patients with primary brain tumors. Neuro-Oncology, 10, 171-181. https://doi.org/10.1215/15228517-2007-057

Barlow, D. (2002). Anxiety and its disorders: The nature and treatment of anxiety and panic (2nd ed.). New York: Guilford Press.

Beck, A. T., \& Steer, R. A. (1993). Beck Depression Inventory Manual. San Antonio, TX: Psychological Corporation.

Beck, A. T., Steer, R. A., \& Brown, G. K. (1996). BDI-II, Beck Depression Inventory: Manual (2nd ed.). Boston, MA: Harcourt Brace. https://doi.org/10.1037/t00742-000

Bjelland, I., Dahl, A. A., Haug, T. T., \& Neckelmann, D. (2002). The validity of the Hospital Anxiety and Depression Scale. An updated literature review. Journal of Psychosomatic Research, 52(2), 69-77. https://doi.org/10.1016/S0022-3999(01)00296-3

Bonelli, R., Dew, R. E., Koenig, H. G., Rosmarin, D. H., \& Vasegh, S. (2012). Religious and spiritual factors in depression: Review and integration of the research. Depression Research and Treatment. https://doi.org/10.1155/2012/962860

Bunevicius, A., Deltuva, V. P., \& Tamasuskas, A. (2017). Association of pre-operative depressive and anxiety symptoms with five-year survival of glioma and meningioma patients: A prospective cohort study. Oncotarget, 8(34), 57543-57551. https://doi.org/10.18632/oncotarget.15743

Bunevicius, A., Tamasauskas, S., Deltuva, V., Tamasauskas, A., \& Bunevicius, R. (2013). Psychological distress symptoms' clusters in brain tumor patients: Factor analysis of depression and anxiety scales. Psycho-Oncology, 22, 2860-2863. https://doi.org/10.1002/pon.3354

Castillo, C. S., Starkstein, S. E., Fedoroff, J. P., Price, T. R., \& Robinson, R. G. (1993). Generalized anxiety disorder after stroke. Journal of Nervous Mental Disease, 181(2), $100-6$. https://doi.org/10.1097/00005053-199302000-00005

Charkavluik, A., Steiblience, V., Tamasauskas, S., Deltuva, V. P., \& Bunevicius, A. (2014). Psychiatric histories and treatment in patients with brain tumors: Association with psychological distress symptoms and health related quality of life. Biological Psychiatry and Psychopharmacology, 16(2), 79-84.

Chirchiglia, D. (2018). Pseudodepression as an anticipatory symptom of frontal lobe brain tumors. International Journal of Depression and Anxiety, 1, 007. https://doi.org/10.23937/IJDA-2017/1710007

Chowdhary, U. M., Ibrahim, A., Sohaibani, M. O., \& Boehme, D. H. (1987). Experience with brain tumors in the Eastern Province of Saudi Arabia. https://doi.org/10.5144/0256-4947.1987.166

D'Angelo, C., Mirijello, A., Leggio, L., Ferrulli, A., Carotenuto, V., Icolaro, N., ... Addolorato, G. (2008). State and trait anxiety and depression in patients with primary brain tumors before and after surgery: 1-year longitudinal study. Journal of Neurosurgery, 108(2), 281-286. https://doi.org/10.3171/JNS/2008/108/2/0281

Ekholm, O., Gundgaaard, J., Rasmussen, N. K. R., \& Hansen, E. H. (2010). The effect of health, socio-economic position, and mode of data collection on non-response in health interview surveys. Scandinavian Journal of Public Health, 38, 699-706. https://doi.org/10.1177/1403494810382474

Hill, N. L., Mogle, J., Wion, R., Munoz, E., DePasquale, N., Yevchak, A. M., \& Parisi, J. M. (2016). Subjective Cognitive Impairment and Affective Symptoms: A Systematic Review. The Gerontologist, 56(6). https://doi.org/10.1093/geront/gnw091

Huang, J., Xiao, J., Zhao, D., Tang, H., Wu, H., \& Chen, J. (2017). Association between depression and brain tumor: A systematic review and meta-analysis. Oncotarget, 8(55), 94932-94943. https://doi.org/10.18632/oncotarget.19843

Hussain, S. K, Lenner, P., Sundquist, J., \& Hemminki, K. (2008). Influence of education level on cancer survival in Sweden. Annals of Oncology, 19(1), 156-62. https://doi.org/10.1093/annonc/mdm413 
Krumpal, I. (2013). Determinants of social desirability bias in sensitive surveys: A literature review. Quality and Quantity, 47(4), 2025-2047. https://doi.org/10.1007/s11135-011-9640-9

Lang, P. J., Davis, M., \& Ohman, A. (2000). Fear and anxiety: Animal models and human cognitive $\begin{array}{lllll}\text { psychophysiology. Journal of Affective Disorders, } & \text { 61, 137-159. }\end{array}$ https://doi.org/10.1016/S0165-0327(00)00343-8

Litofsky, N. S, Farace, E., Anderson, F., Meyers, C. A., Huang, W., \& Laws, E. R. (2004). Depression in patients with high-grade glioma: Results of the glioma outcomes project. Neurosurgery, 54(2), 358-367. https://doi.org/10.1227/01.NEU.0000103450.94724.A2

Mainio, A., Hakko, H., Niemelä, A., Tuurinkoski, T., Koivukangas, J., \& Räsänen, P. (2003). The effect of brain tumour laterality on anxiety levels among neurosurgical patients. Journal Neurology, Neurosurgery, and Psychiatry, 74, 1278-1282. https://doi.org/10.1136/jnnp.74.9.1278

Mainio, A., Tuunanen, S., Hakko, H., Niemelä, A., Koivukangas, J., \& Räsänen, P. (2006). Decreased quality of life and depression as predictors for shorter survival among patients with low-grade gliomas: A follow-up from 1990 to 2003. European Archives of Psychiatry and Clinical Neuroscience, 256, 516-521. https://doi.org/10.1007/s00406-006-0674-2

Moise, D., \& Madhusoodanan, S. (2006). Psychiatric symptoms associated with brain tumors: A clinical enigma. CNS Spectrums, 11(1), 28-31. https://doi.org/10.1017/S1092852900024135

National Cancer Institute at the National Institutes of Health. (2014). Adult brain tumors treatment. Retrieved on July 5, 2014.

National Cancer Institute at the National Institutes of Health. (2014). General information about adult brain tumors. Retrieved on June 8, 2014.

Nugent, B. D., Weimer, J., Choi, C. J., Bradley, C. J., Bender, C. M., Ryan, C. M., ... Sherwood, P. R. (2014). Work productivity and neuropsychological function in persons with skull base tumors. Neuro Oncology Practice, 1(3), 106-113. https://doi.org/10.1093/nop/npu015

Oliveira-Maia, A. J., Ruivo, J., \& Barahona-Corrêa, J. B. (2014). A case of glioblastoma masquerading as an affective disorder. The Primary Care Companion for CNS Disorders, $16(6)$. https://doi.org/10.4088/PCC.14101682

Overcash, J. (2015). Assessing the functional status of older cancer patients in an ambulatory care visit. Healthcare, 3(3), 846-859. https://doi.org/10.3390/healthcare3030846

Pranckeviciene, A., \& Bunevicius, A. (2015). Depression screening in patients with brain tumors: A review. CNS Oncology, 4(2), 71-8. https://doi.org/10.2217/cns.14.60

Pringle, A. M., Taylor, R., \& Whittle, I. R. (1999). Anxiety and depression in patients with an intracranial neoplasm before and after tumour surgery. British Journal of Neurosurgery, 13(1), 46-51. https://doi.org/10.1080/02688699944177

Richter, A., Jenewein, J., Krayenbu, N., Woernle, C., \& Bellut, D. (2016). Are preoperative sex-related differences of affective symptoms in primary brain tumor patients associated with postoperative histopathological grading? Journal of Neuro-Oncology, 126, 151-156. https://doi.org/10.1007/s11060-015-1950-7

Russel, D. S., \& Rubinstein, L. J. (1971). Pathology of tumours of the nervous system (3rd ed.). London: Edward Arnold. https://doi.org/10.1002/path.1711580413

Schubart, J. R., Kinzie, M. B., \& Farace, E. (2008). Caring for the brain tumor patient: Family caregiver burden and unmet needs. Neuro-Oncology, 10(1), 61-72. https://doi.org/10.1215/15228517-2007-040

Shors, T. J., \& Leuner, B. (2003). Estrogen-mediated effects on depression and memory formation in females. Journal of Affective Disorder, 74(1), 85-96. https://doi.org/10.1016/S0165-0327(02)00428-7

Terkawi, A. S., Tsang, S., AlKahtani, G. J., Al-Mousa, S. H., Al Musaed, S., Al Zoraigi, U. S., ... Altirkawi, K.A. (2017). Development and validation of Arabic version of the Hospital Anxiety and Depression Scale. Saudi Journal of Anaesthesia, 11(1), 11-18. https://doi.org/10.4103/sja.SJA_68_17

Wellish, D. K., Kaleita, T. A., Freeman, D., Cloughesy T., \& Goldman, J. (2002). Predicting major depression in brain tumor patients. Psychooncology, 11(3), 230-8. https://doi.org/10.1002/pon.562 
Wiedemann, G., Pauli, P., Dengler, W., Lutzenberger, W., Birbaumer, N., \& Buchkremer, G. (1999). Frontal brain asymmetry as a biological substrate of emotions in patients with panic disorders. Archive of General Psychiatry, 56, 78-84. https://doi.org/10.1001/archpsyc.56.1.78

Wilson, K.A, Waugh, A., Chambers, G., Grant, A., \& Ross, J. (2006). Ross and Wilson anatomy and physiology in health and illness (pp. 53-54). Edinburgh: Churchill Livingstone.

World Health Organization. (2012). The global burden of disease. Retrieved from http://www.who.int/healthinfo/global_burden_disease/GBD_report_full.pdf .

World Health Organization. (2014). World Cancer Report (Chapter 5.16).

Xie, J., Yang, S., Liu, X., \& Zhao, Y. (2018). Effect of marital status on survival in glioblastoma multiforme by demographics, education, economic factors, and insurance status. Cancer Medicine, 7, 3722-3742. https://doi.org/10.1002/cam4.1688

Zigmond, A. S., \& Snaith, R. P. (1983). The hospital anxiety and depression scale. Acta Psychiatrica Scandinavica, 67(6), 361-370. https://doi.org/10.1111/j.1600-0447.1983.tb09716.x

Zulch, K. J, \& Wechsler, W. (1968). Pathology and Classification of Gliomas. In Krayenbuhl H, Maspes P. E, Sweet W. H. (Eds.), Progress in Neurological Surgery (Vol. 2). Basel: Karger.

Zulch, K. J. (1956). Biolgie und pathologie der himgeschwulste. In Olivecrona H., Tonnis W. (Eds.), Handbuch der Neurochirugie (Vol. 3). Berlin: Springer. https://doi.org/10.1007/978-3-642-87789-6_1

\section{Copyrights}

Copyright for this article is retained by the author(s), with first publication rights granted to the journal.

This is an open-access article distributed under the terms and conditions of the Creative Commons Attribution license (http://creativecommons.org/licenses/by/4.0/). 